\title{
Public knowledge, attitude and behavioural changes in an Indian population during the Influenza A (H1N1) outbreak
}

\author{
Shivlingesh Krishnappa Kamate, Anil Agrawal, Harshvardhan Chaudhary, Karanprakash Singh, \\ Prashant Mishra, Kailash Asawa
}

Department of Public Health Dentistry, Pacific Dental College and Hospital, Debari, Udaipur Rajasthan, India

\begin{abstract}
Background: Influenza A $(\mathrm{H} 1 \mathrm{~N} 1)$ is the most recent of the pandemic diseases that has affected the world's population. The aim of this study was to assess knowledge, attitude and behavioural responses of an Indian community toward Influenza A (H1N1).

Methodology: A cross-sectional questionnaire survey was conducted in Udaipur (Rajasthan, India) among 791 individuals (57\% males and $43 \%$ females) from 23 July to 27 August 2009. Outcome measures were perceived seriousness of the disease, opinion about government and health authorities, perceived efficacy of various preventive measures, avoidance behaviours, and increased hygiene maintenance in relation to Influenza A (H1N1).

Results: Of 791 respondents, 83.1\% had heard about Influenza A (H1N1), but 47.4\% felt that they did not have enough information about the pandemic. Only $34.5 \%$ felt that their health would be seriously affected if they contracted Influenza A (H1N1). Over half of the respondents $(59.6 \%)$ had no idea about the duration of the pandemic. Knowledge differed significantly according to gender, age groups, and educational status as well as working status; however, females had better attitude than males. Respondents rated face masks and vaccines as the most effective preventive measures.

Conclusion: Results showed that in spite of having acceptable knowledge and attitude, behavioural response to Influenza A (H1N1) was poor. Therefore, increased efforts should be made by the government to understand what factors are associated with adaptive behaviour changes among the general public. Emphasizing the efficacy of recommended actions and the possible duration of the outbreak may further help to improve public compliance.
\end{abstract}

Key words: Influenza A (H1N1), knowledge, attitude, behaviour

J Infect Dev Ctries 2010; 4(1):007-014.

(Received 13 September 2009 - Accepted 26 November 2009)

Copyright () 2010 Kamate et al. This is an open-access article distributed under the Creative Commons Attribution License, which permits unrestricted use, distribution, and reproduction in any medium, provided the original work is properly cited.

\section{Introduction}

Scientists and policy makers are concerned about the emergence of an influenza pandemic for which we will have neither a strain-specific vaccine nor sufficient antiviral medications at the onset of the outbreak [1]. In April 2009, a new strain of influenza virus $\mathrm{A} / \mathrm{H} 1 \mathrm{~N} 1$, commonly referred to as "swine flu," began to spread in several countries around the world. Evidence that this new strain could pass from human to human led the World Health Organization to quickly raise its pandemic alert level to Phase 5 (29 April 2009) [2], sending "a strong signal that a pandemic is imminent and that the time to finalize the organization, communication and implementation of the planned mitigation measures is short [2]. On 11 June, the alert was subsequently raised to Phase 6 [2], indicating that a full global pandemic was underway. As of
6 August 2009, the World Health Organization reported 1,77,457 laboratory confirmed cases of influenza $\mathrm{A} / \mathrm{H} 1 \mathrm{~N} 1$ and 1,462 deaths [2]. India was no exception and many deaths (138 as of 9 September 2009) were reported in metropolitan cities such as Mumbai, Pune and Bangalore [3].

Given the seriousness of the situation and lack of any specific vaccine against Influenza A (H1N1), mitigation measures in the India have so far focused on identifying, treating, and isolating people who have the disease and educating the public about the steps that individuals can take to reduce the risk of transmission. These recommendations include using tissues when sneezing, washing hands regularly with soap and water, and setting up a network of "flu friends" to provide mutual assistance when someone becomes ill [1]. 
A great deal of cooperation from the public is required to successfully implement these measures. Two relevant factors are prominent in determining whether people adopt precautionary behaviour in response to an outbreak. First, a sense of public distrust exists about journalists and the sensationalizing of health-related stories. People may fail to heed official advice conveyed through the media if they believe that this is "just another health scare." Second, many scientific uncertainties surround Influenza A (H1N1). Such uncertainty may influence whether people undertake precautionary behaviours. Understanding the role of specific perceptions in motivating people to engage in precautionary behaviour may help health communicators to improve their messages about outbreaks of new infectious diseases and specifically Influenza A (H1N1) [1].

Since Udaipur is the most frequently visited city by tourists from various countries, it may be regarded as a potentially high-risk area for the spread of Influenza A (H1N1); hence this city was chosen to assess the public knowledge, attitude and behavioural changes in relation to the Influenza A (H1N1) outbreak.

\section{Materials and Methods}

This cross-sectional study was conducted in Udaipur City, Rajasthan, India. The subjects were assessed using a pre-tested self-administered questionnaire containing the following information:

- Personal demographic characteristics (name, age, gender, educational qualification and working status)

- Awareness of Influenza A (H1N1) situation and perceived personal risk (consisting of 11 questions: 1) ever heard about swine flu; 2) ever heard about H1N1; 3) source of information about Influenza A (H1N1); 4) relation between swine flu and $\mathrm{H} 1 \mathrm{~N} 1$; 5) cause of $\mathrm{H} 1 \mathrm{~N} 1$; 6) awareness about Influenza A (H1N1) situation; 7) self -confidence regarding information about Influenza A (H1N1); 8) duration of the pandemic influenza; 9) self-perceived threat on health by Influenza A (H1N1); 10) confidence toward health authorities regarding the risk of pandemic; confidence toward the government's preparedness in handling influenza pandemic); 11) perceived efficacy of various preventive methods such as herbal remedies, antibiotics, vaccines, face masks, anti-virals, hand washing and quarantine

- Behavioural change in relation to the Influenza A (H1N1) outbreak (consisting of eight questions as follows: six related to avoidance of places or activities such as 1) deliberately cancelled or postponed social event, 2) reducing the number of rides on public transport, 3) taken time off work, 4) reducing the amount of time going into shops, 5) keeping children out of school or nursery, and 6) avoiding crowded places; two related to increased hygiene maintenance such as 1) increased amount of cleaning or disinfecting things that might be touched and 2) washing hands with soap and water more often than usual.)

\section{All responses used tick boxes.}

Udaipur was geographically divided into four zones, and samples of 208 subjects were randomly chosen from each zone. Factories, offices, hospitals, and main market areas were visited in each zone where Health Surveyors spent approximately three hours in each zone at randomly chosen times of the day to recruit the participants. Ethical clearance was obtained from the Ethical Clearance Committee of the Pacific Dental College and Hospital before commencement of the study and written individual informed consent was taken.

For convenience, age was divided into five groups as follows: 18 to 29 years; 30 to 39 years; 40 to 49 years; 50 to 59 years; and $\geq 60$ years. Similarly, educational status was divided into five groups: illiterate; up to primary education; high school education; graduation; and post-graduation.

\section{Statistical analysis}

For the purpose of analysis each question in the knowledge, attitude and behaviour section that was answered positively was given a score of 1 and each question that was answered negatively was given a score of 0. Each question that was answered "Don't know" was given a score of 2, except question number eight (duration of Influenza A/H1N1), in which the answer "Don't know" was given a score of 1 and rest of the options were given score a of 0 . This was done because as of the time that the questionnaire was administered, the exact duration of the pandemic was not known. The individual scores were summed up to yield a total score. The data was 
analyzed using SPSS version 13 software (SPSS Inc., Chicago, IL, USA).

Students $t$ test was used to find the significant difference in the means of knowledge, attitude and behaviour for gender and working status at $\mathrm{p}$ value $<0.05$. One-way ANOVA was used to find the association of knowledge, attitude, and behaviour in relation to different age groups and different literacy rate levels. Karl Pearson's correlation test was used to find the correlation between knowledge, attitude and behaviour.

\section{Results}

A total of 832 adults were contacted, of whom only 813 agreed to participate. A further 22 were excluded due to communication difficulties. The demographic profile of the participants has been shown in table 1 .

\section{Knowledge response}

Of the respondents $83.1 \%$ (657) had heard about swine flu whereas only 40.4\% (320) knew about the H1N1 virus. The maximum number of subjects $(38.6 \%)$ obtained information related to Influenza A (H1N1) from television whereas only $2 \%$ reported that they had heard about Influenza A (H1N1) on radio. However, only $18.2 \%$ (144) knew that swine flu was caused by the H1N1 virus whereas $81.5 \%$ did not think that the terms "swine flu" and "H1N1" were equal and $0.3 \%$ did not know that the meaning of "swine flu" and "H1N1" was the same. There were $48.7 \%$ (385) who were aware that Influenza A (H1N1) was caused by pigs and $52.6 \%$ (416) knew about the Influenza A (H1N1) situation in India, but only $32.4 \%$ (256) believed that they had enough information regarding Influenza A (H1N1). Altogether, $59.6 \%$ had no idea about the duration of the pandemic; $10.1 \%$ (80) thought that it would last less than a month; 20.2\% (160) believed that it would last three to six months; $8.1 \%$ (64) thought that it would last six months to one year; and only $2 \%$ (16) believed that it would last one to two years.

As shown in Table 2, males had significantly more knowledge than females $(\mathrm{p}=0.001$. The results also showed that respondents in the age groups between 40 to -49 years, 30 to 39 years and 18 to 29 years differed significantly in knowledge from respondents in the 50 to 59 years and $\geq 60$ years age groups at $\mathrm{p}=0.001$ (Least Significant
Difference $=0.17) \quad($ Table 3$)$. When educational levels were compared, respondents in illiterate, up to primary education and high school education differed significantly from graduates and post-graduates at $\mathrm{p}=0.001$ (Least Significant Difference $=0.38) \quad($ Table 4$)$. When employment was considered, those who worked differed significantly in knowledge from unemployed subjects at $\mathrm{p}=0.001$ (Table 5).

\section{Attitude response}

Two percent of the respondents were of the opinion that Influenza A (H1N1) would not affect their health; $36.4 \%$ feared that they would be somewhat affected; $34.5 \%$ believed that they would be seriously affected; and $27.1 \%$ had no idea about the effect of Influenza A (H1N1) on their health. Of the respondents, $44.6 \%$ (353) believed that health care authorities were exaggerating the risk of a pandemic and less than half of the respondents $(32.5 \%$; 257) believed that the government would be prepared to quickly and effectively respond to an influenza pandemic.

It was observed that females had a significantly more positive attitude than males ( $p$ $=0.001)$ (Table 2). Respondents in all age groups differed significantly in attitude at $p=0.001$ (Least significant Difference $=0.23) \quad($ Table 3$)$. Comparing literacy level, respondents who were illiterate and who had completed primary education differed significantly in attitude at $\mathrm{p}=$ 0.001 (Least Significant Difference=0.118) (Table 4). However, it was seen that unemployed respondents had significantly more positive attitudes than those who were employed at $\mathrm{p}=$ 0.001 (Table 5).

\section{Behavioural response to Influenza A (H1N1) outbreak}

Of the respondents, $59.5 \%$ (471) had not cancelled or postponed any social event; $67.6 \%$ (535) had not reduced the use of public transportation; $74.3 \%$ (583) had not taken any time off work; $81.8 \%$ (647) had no problem going to grocery shops; and $83.8 \%$ (663) had no objection in sending their children to school. However, more than half the respondents $(52.6 \%$; $416 / 791$ ) avoided crowded places and $54.6 \%$ (432) washed their hands with soap and water more often than usual, and $63.6 \%$ (503) were not overtly worried about cleaning or disinfecting things that they might touch. 
Table1. Demographic characteristics of the participants $(n=791)$.

\begin{tabular}{|llcc|}
\hline \multicolumn{1}{c}{ Characteristics } & Mumber & Percentage \\
& Mex & 451 & $57 \%$ \\
Age group (years) & Female & 340 & $43 \%$ \\
& $18-29$ & 225 & $28.4 \%$ \\
& $30-39$ & 260 & $32.9 \%$ \\
& $40-49$ & 96 & $12.1 \%$ \\
Educational level & $50-59$ & 129 & $16.3 \%$ \\
& $\geq 60$ & 81 & $10.2 \%$ \\
& Illiterate & 161 & $20.3 \%$ \\
& Up to primary & 214 & $27.1 \%$ \\
& education & & \\
& High school education & 128 & $16.2 \%$ \\
& Graduation & 208 & $26.3 \%$ \\
Occupational status & 80 & $10.1 \%$ \\
& Post-graduation & 207 & $26.2 \%$ \\
& Working & 584 & $73.8 \%$ \\
\hline
\end{tabular}

Table 2. Association of gender with knowledge, attitude and behaviour using Students $t$ test.

\begin{tabular}{|ccccccc|}
\hline & Gender & No. & Mean & SD & SE & P value \\
KS & Male & 451 & 4.35 & 1.890 & 0.65 & $0.000^{*}$ \\
& Female & 340 & 3.79 & 1.983 & & \\
AS & Male & 451 & 1.42 & 1.125 & 0.44 & $0.000^{*}$ \\
& Female & 340 & 1.53 & 1.342 & & \\
BS & Male & 451 & 3.24 & 1.671 & 0.29 & $0.000^{*}$ \\
& Female & 340 & 2.14 & 1.877 & & \\
\hline
\end{tabular}

Table 3. Association of age with knowledge, attitude and behaviour using one-way ANOVA.

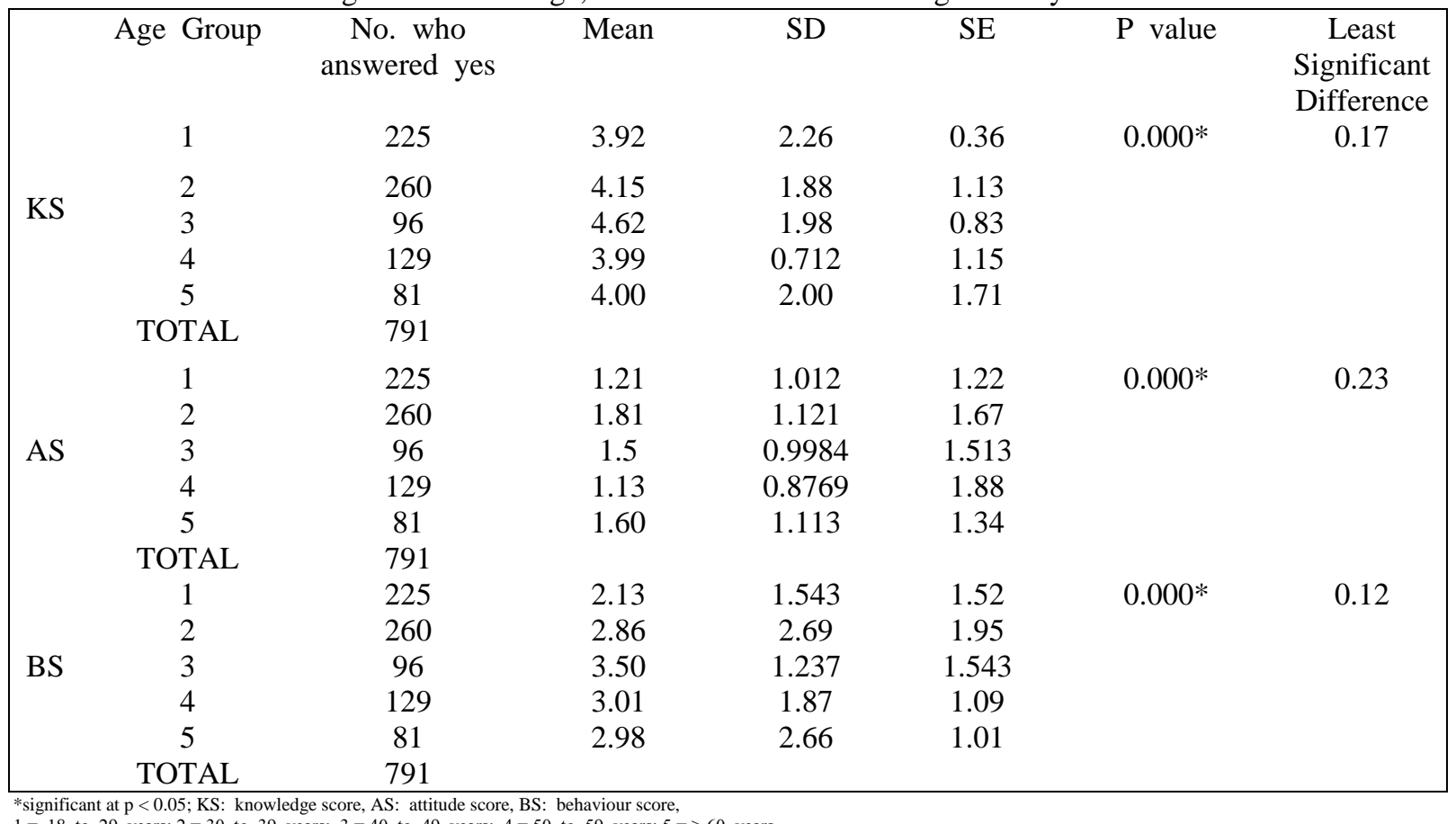

$1=18$ to 29 years; $2=30$ to 39 years; $3=40$ to 49 years; $4=50$ to 59 years; $5=\geq 60$ years. 
Table 4. Association of education with knowledge, attitude and behaviour using one-way ANOVA.

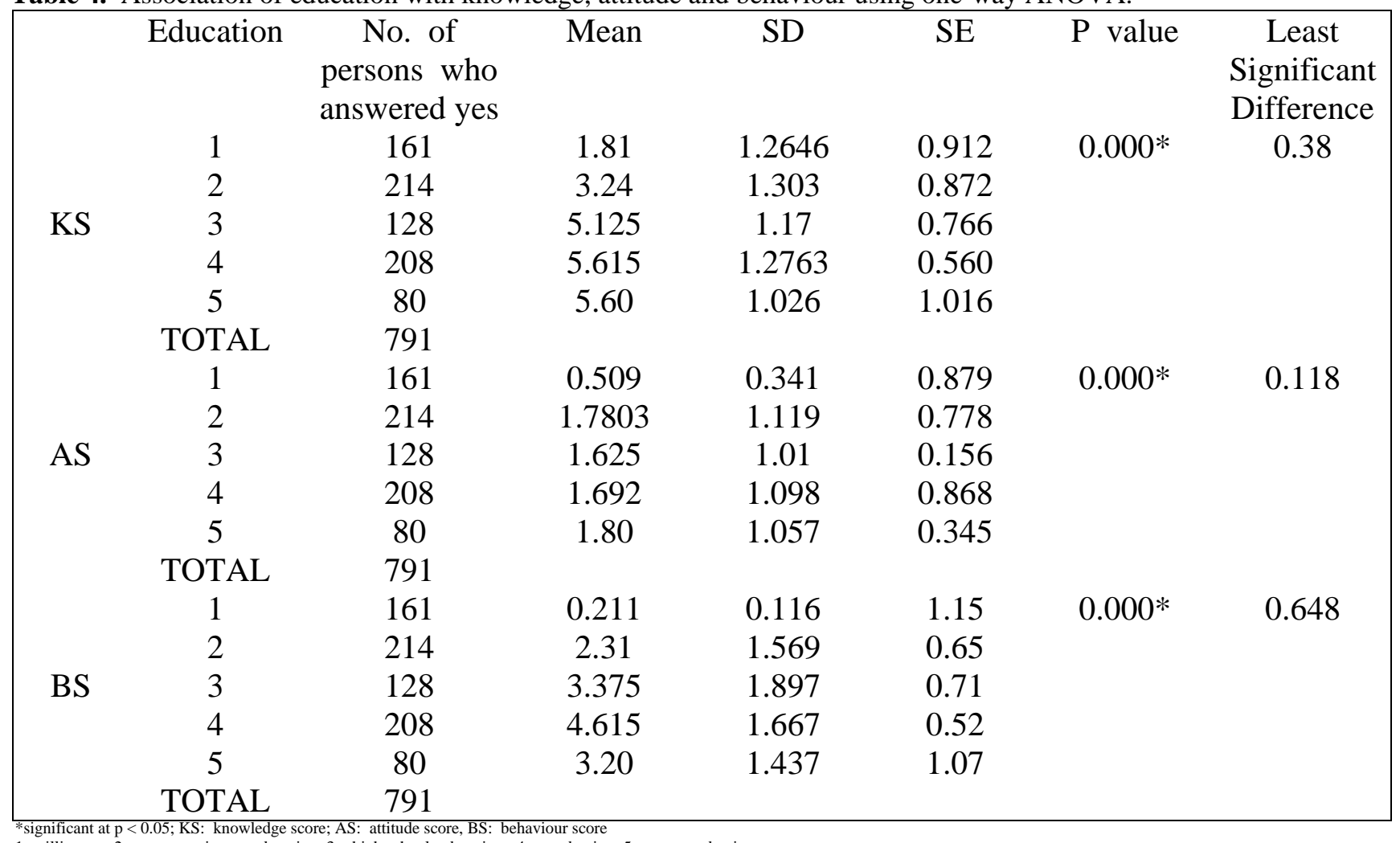

$1=$ illiterate; $2=$ up to primary education; $3=$ high school education; $4=$ graduation; $5=$ post-graduation.

Table 5. Association of working / non-working status with knowledge, attitude and behaviour using Students $t$ test.

\begin{tabular}{|ccccccc|}
\hline \multirow{3}{*}{ KS } & Working Status & No. & Mean & SD & SE & P value \\
& Working & 207 & 5.25 & 1.7207 & 1.287 & $0.000^{*}$ \\
AS & Non working & 584 & 3.72 & 1.871 & & $0.000^{*}$ \\
& Working & 207 & 1.460 & 0.6385 & 1.762 & $0.000^{*}$ \\
& Non working & 584 & 1.480 & 1.093 & & 0.768 \\
\end{tabular}

*significant at $\mathrm{p}<0.05 . \mathrm{KS}$ : knowledge score: AS: attitude score: BS: behaviour score

Table 6. Correlation between knowledge, attitude and behaviour using Karl Pearson's correlation test.

\begin{tabular}{|c|c|c|c|}
\hline S. & \multicolumn{2}{|c|}{ Relationship between } & Karl Pearson's coefficient of \\
\hline 1 & Knowledge score & Attitude score & +0.512 \\
\hline 2. & Knowledge score & Behaviour score & +0.6079 \\
\hline 3. & Behaviour score & Attitude score & +0.4485 \\
\hline
\end{tabular}


It was found that males engaged in one form or another of avoidance behaviours significantly more than females at $\mathrm{p}=0.001$ (Table 2). Respondents in age groups 18 to 29 years, 30 to 39 years, and 40 to 49 years differed significantly in behavioural response compared to respondents in age groups 50 to 59 years and $\geq 60$ years at $p$ $=0.001$ (Least significant difference $=0.12$ ) $($ Table $3)$. Regarding education level, illiterate as well as all groups of literates differed significantly in behavioural response at $\mathrm{p}=0.001$ (Least Significant Difference $=0.648$ ) $($ Table 4). In relation to working status, it was found that workers differed significantly from non-workers at $\mathrm{p}=0.001$ (Table 5).

Correlation between knowledge, attitude and behaviour

A linear relationship was found between knowledge and attitude, knowledge and behaviour, and attitude and behaviour using Karl Pearson's correlation coefficient (Table 6).

Perceived efficacy of various preventive methods for Influenza A (H1N1)

Vaccines (36.4\%) and face masks (36.6\%) were rated as the most effective methods for the prevention of Influenza A (H1N1), whereas herbal remedies $(38.6 \%)$ and anti-virals $(22.3 \%)$ were rated as the least effective (Figure 1).

\section{Discussion}

In spite of the increase in the number of Influenza $\mathrm{A}(\mathrm{H} 1 \mathrm{~N} 1)$ cases as well as the response of the WHO by raising its pandemic alert status to phase 6 and extensive media coverage, public responses to Influenza $A(\mathrm{H} 1 \mathrm{~N} 1)$ were muted. In practice, convincing the public that the threat is real is often a more pressing task for public health agencies than providing reassurance [1]. About one third of the respondents believed that they had enough information about Influenza A (H1N1) and the rest answered in the negative. These results suggest that public health communicators had some success in preventing confusion and in conveying a consistent set of comprehensible messages which is in confirmation with the study conducted by James Rubin et al. [4].

It was found that males had significantly higher knowledge compared to females. This difference could be due to the fact that males usually had more interaction and socialization than females. This holds particularly well for a country such as India where traditional norms and customs discriminate against females. Similar findings were seen in a study conducted by Salehi Leili et al. in 2008 [5]. When the effect of age was considered, older respondents had better knowledge than younger respondents. Those who were employed had significantly more knowledge than unemployed respondents. Again this is due to the fact that females comprised $43 \%$ of the sample size. Moreover, people who were employed had more access to information through interaction with other people at workplaces than those unemployed. Considering the influence of education on knowledge, it was found that knowledge increased significantly from illiteracy to high school level, but no significant difference in knowledge was found between graduates and postgraduates, which shows that high school education was the threshold/. Similar effects were observed in a study conducted by Syed Farid-ul-Hasnain et al. in 2009 where age, employment and education had significant influence on knowledge [6].

Considering attitude, many people believed that the Influenza A (H1N1) situation was exaggerated by health authorities and the media. Moreover, about half of the respondents were not confident that the government could effectively tackle the pandemic situation in the country. This is in contrast to the study conducted in Hong Kong where a high proportion of the respondents believed that their government was prepared to respond quickly and effectively to any pandemic situation, which could have positive implications for compliance with official advice [8] and further implies that problems with people not complying with official or government advice could be encountered in India. However, a majority (70.9\%) of the respondents were of the view that once they were infected with Influenza A (H1N1) it would affect their health, with $36.4 \%$ believing that it would only somewhat affect them and 34.5\% believing it would seriously affect them, which is consistent with the study conducted by Holly Seale et al. in 2009 [7]. As might be expected, believing that catching Influenza $\mathrm{A}(\mathrm{H} 1 \mathrm{~N} 1)$ will have severe consequences was associated with significant behaviour change [8-10], which shows that even though some of the respondents felt that the disease could affect them, they still had their

Figure 1. Perceived efficacy of various preventive methods for Influenza A (H1N1). 


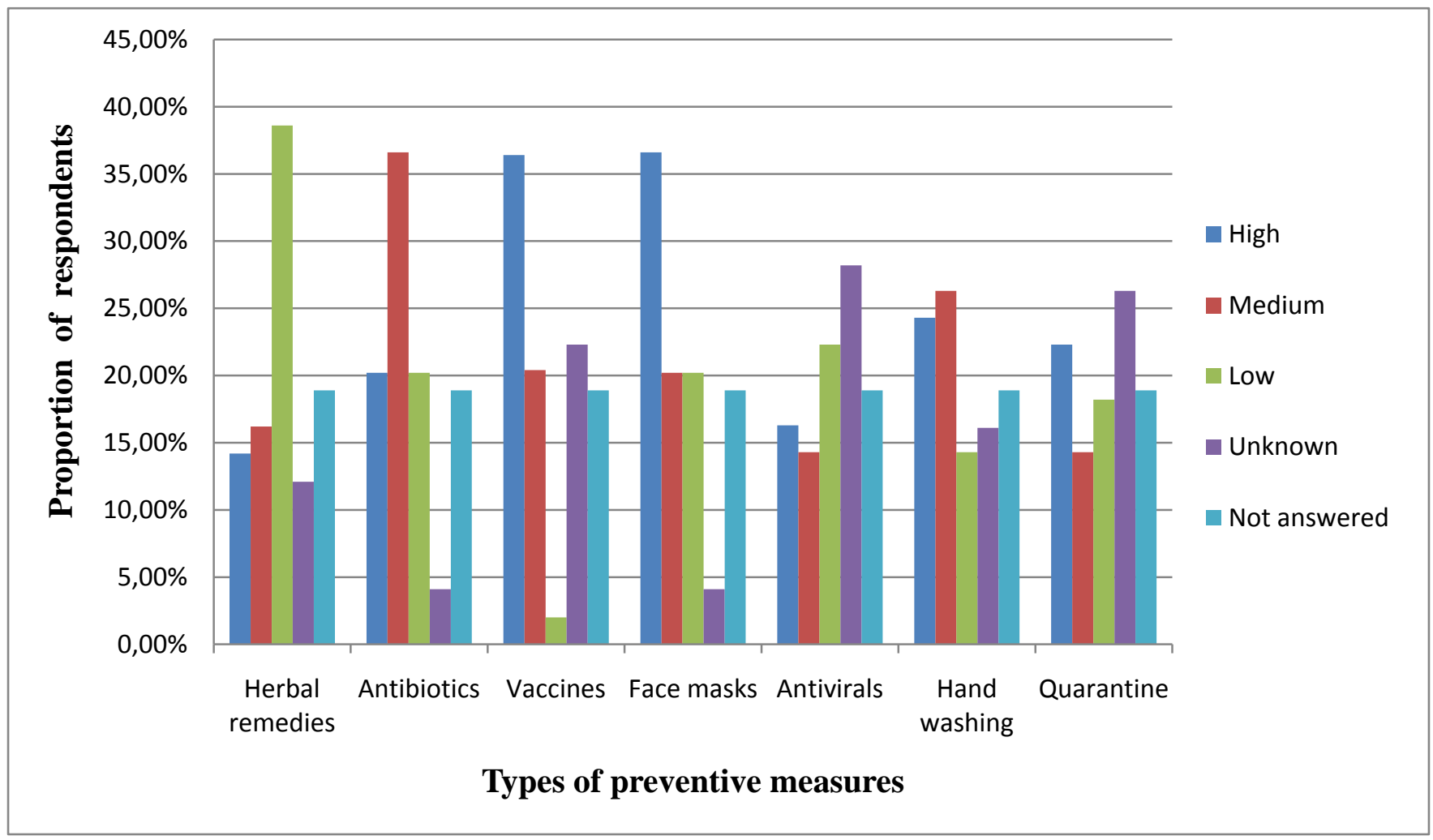

reservations about the risk of the pandemic. Previous studies suggest that compliance with health-related recommendations will increase if people believe they have a high likelihood of being affected or if they perceive the illness to have severe consequences $[8,11]$. It has also been reported that perception or belief about an outbreak may be important in determining compliance with official advice [12]. As in the case of knowledge, attitudes increased significantly as age increased. However, it was found that females had significantly more positive attitudes than males in spite of having less knowledge than males. This finding was consistent with the study conducted by Syed Imran Ahmed et al. in 2009 [13].

Behavioural changes were limited. Most people had not cancelled or postponed any social event, had not reduced the use of public transport, had not taken any time off work, had no problem going to a grocery shop, had no objection in sending their children to school, and were not overtly worried about cleaning or disinfecting things that they might touch. These findings are similar to those observed in the study conducted by James Rubin et al. in 2009 [4]. As might be expected, the perception that the Influenza A (H1N1) situation had been exaggerated was associated with a lower likelihood of behaviour change. Correcting such a perception in the short term may not be easy [14].

Regarding perceived efficacy of various preventive measures, respondents in the current study rated face masks, followed by vaccines, as the most effective methods for prevention of Influenza A (H1N1). Lau et al. [15] also reported that the respondents in their study considered face masks the most effective preventive measure. Conversely, respondents in a study by Seale et al. [7] rated quarantine as the most effective measure for preventing Influenza A (H1N1). Herbal remedies and anti-virals were rated least effective in our study.

Correlation between knowledge, attitude and behaviour

The correlation coefficient of 0.6079 was found between knowledge and behaviour, suggesting that an increase in knowledge would lead to increase in behavioural changes. Therefore, the significant differences that existed between gender and age groups in knowledge coexisted in behaviour. The correlation coefficient 
of 0.4485 was found between attitude and behaviour, again suggesting that an increase in positive attitude led to an increase in behavioural changes. Between knowledge and attitude, a correlation coefficient of 0.512 was found, which again suggested that increased knowledge led to increased positive attitude. These findings are similar to the traditional health education model (KAB model) which suggests that acquiring new knowledge would alter attitudes and lead to a change in behaviour [16]. This somewhat simplistic representation of human behaviour rarely exists in the real world. In reality, a very complex relationship operates between the three domains of learning. Therefore, the findings of this study need to be validated by further studies.

\section{Limitations}

Our study had many limitations. First, it was conducted in a single city. Additional research into differing reactions to the outbreak among other ethnic groups is required. Second, our study sample has the potential to be biased towards community members who are particularly concerned about Influenza A (H1N1). Our survey measured a specific population's views at a specific point in time; their beliefs and attitudes reflect the information available at the time and therefore are not stable. It is unknown whether responses given to the hypothetical situations posed in the survey would accurately reflect the respondents' real-world responses. Third, the perceived seriousness and vulnerability could not be measured in our study. Fourth, our selection of behaviour outcome measures deliberately avoided two of the key factors communicated to the public during the outbreak: the use of tissues when sneezing and what to do if flu-like symptoms develop. Given our sample size and the prevalence of Influenza $\mathrm{A}(\mathrm{H} 1 \mathrm{~N} 1)$ at the time of the survey, we were unable to assess the set of behaviours regarding flu-like symptoms. Use of tissues was not included as this behaviour is important for the protection of others rather than oneself and hence may be qualitatively different in terms of its relation with predictor variables.

\section{Conclusion}

At the time of this study, there were no high levels of morbidity and mortality due to Influenza A (H1N1) in India, but currently both have increased considerably $(1,206$ deaths reported up to 27 January 2010) [3]. The perception that government warnings or media stories represent scare mongering may be difficult to tackle but requires further attention. Another matter of concern is that many of the respondents did not have confidence that the government could handle the Influenza A (H1N1) pandemic effectively. Therefore, increased efforts should be made by the government to understand what factors are associated with adaptive behaviour changes among the public to help communicators to devise more effective public health messages. Equally, understanding how the public responds to the reports of a potential pandemic may also be useful in identifying ways of encouraging behaviour change during the early stages of any future outbreak of infectious disease.

Our results largely endorse the current policy of providing the public with clear, consistent information that focuses on the practical things people can do to reduce their risk and which maintains trust by explicitly discussing the current level of knowledge, preparation, and resources available to tackle the outbreak. Emphasising the efficacy of recommended actions and the possible duration of the outbreak may help to improve compliance further.

\section{References}

1. Blendon RJ, Koonin LM, Benson JM, et al. (2008) Public response to community mitigation measures for pandemic influenza. Emerg Infect Dis 14: 778-786.

2. World Health Organization. Current WHO phase of pandemic alert 2009.

www.who.int/csr/disease/avian_influenza/phase/en/index.ht ml. Accessed on 09/09/2009

3. Ministry of Health and Family Welfare, India. Available on http://mohfw.nic.in/press_releases_on_swine_flu.htm. Accessed on 27/01/2010.

4. Rubin GJ, Amlôt R, Page L, Wessely S (2009) Public perceptions, anxiety, and behavior change in relation to the swine flu outbreak: cross sectional telephone survey. BMJ 339: 2651.

5. Leili S, Elham S, Farkhonde S (2008) A population-based survey of HIV/AIDS knowledge and attitudes in general public, Bandar-Abbas, Iran. Pak J Med Sci 24: 838-44.

6. Farid-ul-Hasnain S, Johansson E, Krantz G (2009) What do young adults know about the HIV/AIDS epidemic? Findings from a population based study in Karachi, Pakistan. BMC Infectious Diseases 9: 38.

7. Seale H, McLaws M-L, Heywood AE (2009) The community's attitude towards swine flu and pandemic influenza. Medical Journal of Australia 191: 267-9.

8. Tang CS-K, Wong C-Y (2004) Factors influencing the wearing of facemasks to prevent the severe acute 
respiratory syndrome among adult Chinese in Hong Kong. Prev Med 39: 1187-1193.

9. Leung GM, Quah S, Ho L-M, Ho S-Y, Hedley AJ, Lee H-P, et al (2004) A tale of two cities: community psychobehavioural surveillance in Hong Kong and Singapore during the severe acute respiratory syndrome epidemic. Infect Control Hosp Epidemiol 25: 1033-41.

10. Brewer NT, Chapman GB, Gibbons FX, Gerrard KD, McCaul KD,Weinstein ND (2007) Meta-analysis of the relationship between risk perception and health behaviour: the example of vaccination. Health Psychol 26: $136-45$.

11. Tang CS-K, Wong C-Y (2003) An outbreak of the severe acute respiratory syndrome: predictors of health behaviours and effect of community prevention measures in Hong Kong, China. Am J Public Health 93: $1887-1888$.

12. Leung GM, Ho L-M, Chen SKK, Ho S-Y, BaconShone J, Choy RYL et al. (2005) Longitudinal assessment of community psychobehavioural responses during and after the 2003 outbreak of severe acute respiratory syndrome in Hong Kong. Clin Infect Dis 40:1713-20.
13. Syed Imran Ahmed, Mohamed Azmi Hassali, Noorizan Abdul Aziz (2009) An Assessment of the Knowledge, Attitudes, and Risk Perceptions of Pharmacy Students Regarding HIV/AIDS. Am J Pharm Educ. 73: 15.

14. Sandman PM (2009) Pandemics: good hygiene is not enough. Nature 459: 322-3.

15. J T F Lau, X Yang, H Tsui, J H Kim (2003) Monitoring community responses to the SARS epidemic in Hong Kong: from day 10 to day 62, J Epidemiol Community Health 57: 864-870

16. Daly (2002) Text book of Essentials in Dental Public Health, 1st edition. New York: Oxford University press 153 p.

\section{Corresponding Author}

Dr. Shivlingesh KK

Boys Hostel Pacific Dental College and Hospital

Debari, Udaipur, Rajasthan, India

Phone: 09784764339

Email: shivgesh@yahoo.com

Conflict of interest: No conflict of interest is declared. 